\title{
THE USE OF N-ACETYL CYSTEINE AS AN ADJUVANT TO SOFT INDUCTION IN CASES PREPARED FOR ICSI IMPROVES CYCLE PARAMETERS; A RANDOMIZED CONTROLLED STUDY
}

\author{
Gaafar Sh, Shaala S, Anwar M, El-Gezery D, Baghdady E. El-Maghraby H, \\ and Abd Elsamie A.A. \\ Department of Obstetrics \& Gynecology, Faculty of Medicine, Alexandria University \\ and Alexandria IVF / ICSI Center
}

\section{ABSTRACT}

Objective: The aim of this study was to evaluate the effect of N-Acetyl-Cysteine (NAC) as an adjuvant therapy 10 ovulation induction using the low fixed dose human menopausal gonadotropins (HMG) in cases prepared for ICSI.

Design : prospective randomized controlled study.

Materials and methods: The study was conducted on 40 patients. The selected cases were less than 40 years old and were diagnosed as having tubal or male factor infertility planned for ICSI. The patients were randomly divided into Iwo equal groups: a control group and a study group. Both groups received 150 IU HMG per day from cyele day two till the day of human chorionic gonadotropins (HCG). In addition, the study group received NAC, $1200 \mathrm{mg}$ daily in three divided doses form cycle day two till the day of HCG. Patients were monitored using serial transvaginal sonography. Before administration of HCG the serum level of oestradiol and progesterone were measured. Testosterone wals measured in the follicular fluid.

Results: The NAC group showed a significant decrease in the HMG requirements (18.3 Vs. 20 ampoules). NAC Ied 10 a significant increase in the final serum oestradiol level $(1375 \mathrm{pg} / \mathrm{ml}$ Vs. $793 \mathrm{pg} / \mathrm{ml})$. The number of the retrieved oocytes was higher (non-significant) in the study group; it resulted in a signilicant increase in the number of mature oocytes and higher rate of fertilization. NAC led to an insignificant drop in follicular fluid testosterone. However, these positive effects of NAC did not lead to a significant change in the pregnancy rate.

Conclusion: The use of NAC as an adjuvant to the low fixed dose gonadotropin protocol in cases prepared for ICSI improved cycle parameters but it did not result in a significant effect on follicular fluid testosterone concentration or the pregnancy rates.

Key words: N-acetyl cysteine, ICSI, Gonadotropins.

\section{INTRODUCTION}

The term friendly in vitro fertilization (IVF) was introduced by Olivennes and Frydman in 1998. The concept is to offer the patients the chance to conceive using procedures which are less in the terms of physical, emotional and financial burden. Protocols of friendly IVF include; natural cycle IVF, clomiphene citrate induction protocols and low dose gonadotropin controlled ovarian hyperstimulation.
These friendly protocols are associated with; very low incidence of multiple gestation, close to zero risk of ovarian hyperstimulation syndrome not to mention the lower costs ${ }^{(1)}$.

However, the low success rate, as compared to the classical long agonist protocol, is considered a major disadvantage of this protocol. The average pregnancy rate of natural cycle IVF reaches $7.2 \%$ per started cycle ${ }^{(2)}$. Low-grade stimulation using clomiphene citrate or low dose gonadotropin controlled ovarian 
hyperstimulation $(\mathrm{COH})$ is proposed to maximize the results of friendly IVF by producing more than one oocyte without substantial increase in the costs or the side effects ${ }^{(3)}$.

The role of the follicular androgens in early follicular development is complex. At low concentrations, androgens enhance their own aromatization and contribute to oestrogen production. At higher levels, the limited capacity of aromatization is overwhelmed, and the follicle becomes androgenic and ultrimately atretic ${ }^{(4)}$. So, the success of a follicle depends on its ability to convert an androgen-dominated microenvironment to an oestrogen-dominated microenvironment ${ }^{(5)}$.

Previous studies have suggested that follicular endocrine environment is related to oocyte maturity in women (MacNatty et al, 1979; Van Dessel et al, 1996). The final phase of oocyte meiotic and cytoplasmic maturation is affected by the intrafollicular concentrations of steroid hormones $(6,7)$, So it was suggested that the intrafollicular concentrations of these steroids is likely to be related to the success or failure of the developmental processes in the oocytes that are necessary for its fertilization and developmental competence ${ }^{(8)}$.

There has been extensive published data that suggest that follicular testosterone functions as a follicular regulator, entancing follicular aromatase activity when adequate amounts of FSH are available ${ }^{(9)}$. Teissier et.al. demonstrated that high follicular fluid testosterone concentration is associated with low success rates in cases prepared for intracytoplasmic sperm injection (ICSI) ${ }^{(10)}$.

$\mathrm{N}$-Acelyl-Cysteine (NAC) is an acetylated form of the amino acid cysteine. NAC is a powerful antioxidant and a premier antitoxin and immune support substance. The key to the antioxidunt power of NAC is due to its role as a precursor of glutathione. Glutathione peroxidase is one of the body's most important naturally occurring antioxidants (11).

Follicular atresia in the ovary is a natural phenomenon, eventually leading to exhaustion of the pool of primordial follicles. The discovery that this process is due to apoptosis has led to extensive research on follicular cell death. Many antioxidants have been used to improve ovulation. Their role is mainly via their effects on apoptosis and cell mitosis $^{(12)}$.

Whether ovarian tissue survival could be improved in the short-term cultures by suppressing apoptosis was studied. NAC was chosen, as an antioxidant, and a potential inhibitor of apoptosis. becauses: (i) it is a well-established inhibitor of physiological ceil death in several other systems and a compound known to act on granulosa cells as a survival factor, (ii) on the basis of the previous studies on human testicular tissue, it is known that NAC penetrates the tissue very well and remains effective in the cultures, and (iii) it is a widely used. clinically safe drug. Interestingly, it was found that cell death in cultured human ovarian cortex wats suppressed by NAC. These findings were consistent with previous studies showing that NAC inhibits apoptosis in cultured porcine ovarian primordial germ cells in rat ovarian follicles (13).

In a prospective placebo controlled study done in 2002, by Fulghesu et al, it was proved that N-Acetyl Cysteine decreases both total, and free serum androgen levels in addition to improving insulin sensitivity in patients having polycystic ovarian disease. The effect of NAC on serum androgens may be considered as a newly discovered mechanism of action of NAC that needs further studies (14).

The proposed study, to our knowledge, is the first published study investigating the effect of $\mathrm{N}$-alcelyl Cysteine (NAC) as a potential adjuvan to HMG induction protocol in cases prepared for ICSI. 


\section{AIM OF THE WORK}

The aim of this study was to evaluate the effect of NAC, as an adjuvant therapy to ovulation induction using the low fixed dose human menopausal gonadotropins (HMG) in cases prepared for ICSI. The study evaluated the effect of NAC on follicular fluid testosterone level, number of mature oocytes, fertilization rate and pregnancy rates.

\section{MATERIALS \& METHODS}

The study was conducted on 40 patients attending El-Shatby Maternity University hospital, Alexandria, Egypt. The selected patients were less than 40 years old and were diagnosed as having tubal or male factor infertility planned for ICSI. Patients suffering from polycystic ovarian syndrome were excluded.

After taking an informed consent, the patients were randomly divided into two equal groups: a control group and a study group. Both groups received 150 IU HMG per day from cycle day two till the day of human chorionic gonadotropins (HCG) in addition the study group received NAC, $1200 \mathrm{mg}$ daily on three divided doses from cycle day two till the day of HCG. Patients were monitored using serial transvaginal sonography. Before administration of HCG the serum level of oestradiol and progesterone were measured.

HCG was administered when the size of the leading follicle exceeds $18 \mathrm{~mm}$, serum oestradiol level exceeds $200 \mathrm{pg} . / \mathrm{ml}$ for each follicle more than $15 \mathrm{~mm}$ in diameter and endometrial thickness is more than $9 \mathrm{~mm}$. Patients were given i.m. 10,000 IU of HCG. Ultrasound guided oocyte retrieval was done 32 hours after HCG and ICSI was performed according to the routine laboratory procedures.

Testosterone concentration in the follicular fluid was measured by using ElAgen Testosterone kits (Ref. No. LI4011K, Adaltis Italia). This kit is used commercially for quantitative measurement of human serum testosterone. The precision of the kit is between $4-9 \%$ and the lower limit of detection of the kit is approximately $0.1 \mathrm{ng} / \mathrm{ml}$. Due to the relatively high concentration of follicular fluid testosterone the samples were diluted 1 in 10.

\section{RESULTS}

Both groups were matched regarding the demographic data with mean age 30.55 years in the control group Vs 31 in the study group. There was not any significant difference between the two studied group regarding the actiology of infertility and the basal hormonal profile.

The NAC group showed a significant decrease in the HMG requirements (18.3 Vs 20 ampoules). NAC led to a significant increase in the final serum oestradiol level (1375 pg/ ml Vs $793 \mathrm{pg} / \mathrm{ml})$ but it did not lead to a statistically significant elfect on serum progesterone levels on the day of HCG administration $(p>0.1)$.

The number of the retrieved oocytes was higher in the study group (mean 5.39) than the control group (mean 3.58) but this difference did not reach a statistical significance $(p>0.1)$ however, NAC resulted in a significant increase in the number of mature occytes $(\mathrm{p}<0.001)$. Moreover fertilization rate was statistically significantly higher in the NAC group $(\mathrm{p}<0.01)$.

In addition, the cancellation rate dropped from $60 \%$ in the control group to $30 \%$ in the NAC group $(\mathrm{p}<0.05)$. The most important cause of cancellation was immature oocytes (six cases in the control group \& three cases in the study group). Four cases in the control group were cancelled due to poor ovarian response; however, there were no cases of poor response in the study group. A total of three cases were cancelled due to spontaneous ovulation of which one was only present in the study group. 
NAC led to an insignificant drop in follicular fluid testosterone from $17.43 \mathrm{ng} / \mathrm{ml}$ in the control group to $14.8 \mathrm{ng} . \mathrm{ml}$ in the study group. In both groups the level of follicular fluid testosterone was slightly lower in the pregnant females in both the study and control groups. But these differences were statistically insignificant.

However, these positive effects of NAC did not lead to a significant change in the pregnancy rate
(25\% in the control group and $20 \%$ in the study group per started cycle).

There were two cases of twin pregnancy in the control group and no cases of higher order pregnancies. On the other hand, all pregnancies in he study group were singleton pregnancies. There was only one case of mild ovarian hyperstimulation syndrome in the study group and no cases occurred in the control group.

Table I : Demographic and clinical data of the two studied groups.

\begin{tabular}{|c|c|c|c|c|}
\hline Parameter & \multicolumn{2}{|c|}{ Control group } & \multicolumn{2}{|c|}{ Study group } \\
\hline Age & \multirow{2}{*}{\multicolumn{2}{|c|}{$24-39$}} & & \\
\hline Range & & & \multicolumn{2}{|c|}{$20-39$} \\
\hline Mean & \multicolumn{2}{|c|}{30.55} & \multicolumn{2}{|c|}{31} \\
\hline \pm S.D. & \multicolumn{2}{|c|}{4.75} & \multicolumn{2}{|c|}{5.77} \\
\hline $\mathrm{t}$ & \multicolumn{4}{|c|}{0.98} \\
\hline $\mathrm{p}$ & \multicolumn{4}{|c|}{0.39} \\
\hline \multicolumn{5}{|l|}{ Body mass index } \\
\hline Range & \multicolumn{2}{|c|}{$24.5-29.2$} & \multicolumn{2}{|c|}{$24.9-29.1$} \\
\hline Mean & \multicolumn{2}{|c|}{26.5} & \multicolumn{2}{|c|}{27.03} \\
\hline $\pm S . D$ & \multicolumn{2}{|c|}{1.36} & \multicolumn{2}{|c|}{2.03} \\
\hline $\mathrm{t}$ & \multicolumn{4}{|c|}{0.98} \\
\hline $\mathrm{P}$ & \multicolumn{4}{|c|}{0.33} \\
\hline Cause of infertility & & & & \\
\hline Miale lictor & 13 & $65.0 \%$ & 14 & $60.0 \%$ \\
\hline Tubal lictor & 7 & $35.0 \%$ & 6 & $40.0 \%$ \\
\hline$x^{2}$ & \multicolumn{4}{|c|}{0.11} \\
\hline $\mathrm{p}$ & \multicolumn{4}{|c|}{0.78} \\
\hline \multicolumn{5}{|l|}{ Duration of infertility in years } \\
\hline Ringe & \multicolumn{2}{|c|}{$2-11$} & \multicolumn{2}{|c|}{$2-23$} \\
\hline Mean & \multicolumn{2}{|c|}{5.5} & \multicolumn{2}{|c|}{7.55} \\
\hline $\pm S . D$. & \multicolumn{2}{|c|}{2.40} & \multicolumn{2}{|c|}{4.98} \\
\hline \multirow[b]{2}{*}{$\mathrm{p}$} & \multicolumn{4}{|c|}{1.72} \\
\hline & \multicolumn{4}{|c|}{0.06} \\
\hline
\end{tabular}


Table II : Comparison between the two studied groups regarding the number of ampoules used.

\begin{tabular}{|l|c|c|}
\hline & Control group & Study group \\
\hline Number of ampoule used & & \\
Range & $14-26$ & 1622 \\
Mean & 20.0 & 18.3 \\
\pm S.D. & 3.43 & 2 \\
\hline $\mathrm{t}$ & & 1.82 \\
$\mathrm{p}$ & & $0.03 *$ \\
\hline
\end{tabular}

* Statistically significant

Table III : Comparison between the two studied groups regarding maturity.

\begin{tabular}{|l|c|c|}
\hline & Control group & Study group \\
\hline GV & 5 & 12 \\
M1 & 1 & 7 \\
M2 & 35 & 75 \\
Fractured & 1 & 5 \\
\hline Total & 42 & 99 \\
\hline t & \multicolumn{2}{|c|}{7.650} \\
p & \multicolumn{2}{|c|}{$0.001 *$} \\
\hline
\end{tabular}

* Statistically significant

Table IV : Comparison between the two studied groups regarding fertilization.

\begin{tabular}{|c|c|c|}
\hline & Control group & Study group \\
\hline Total number & 24 & 60 \\
Range & $1-5$ & $1-19$ \\
Mean & 3.0 & 4.0 \\
IS.D. & 1.41 & 4.181 \\
\hline Z & & 5.65 \\
P & & $0.01 *$ \\
\hline
\end{tabular}

:Statistically signilicim 
Table V : Comparison between the two studied groups regarding outcome per cycle.

\begin{tabular}{|c|c|c|c|c|c|}
\hline & \multicolumn{2}{|c|}{$\begin{array}{l}\text { Control group } \\
\qquad \mathrm{n}=20^{66}\end{array}$} & \multicolumn{2}{|c|}{$\begin{array}{l}\text { Study group } \\
6 \mathrm{n}=20^{66}\end{array}$} & \multirow[t]{2}{*}{$\mathbf{P}$} \\
\hline & No. & $\%$ & No. & $\%$ & \\
\hline Complete & 8 & 40.0 & 14 & 70.0 & $0.024^{*}$ \\
\hline pregnant & 5 & 25.0 & 4 & 20.0 & 0.35 \\
\hline Cancelled & 12 & 60.0 & 6 & 30.0 & $0.021 *$ \\
\hline
\end{tabular}

* Statistically significant

Table VI : Comparison between the two studied groups regarding cancellation reason.

\begin{tabular}{|c|c|c|c|c|c|}
\hline & \multicolumn{2}{|c|}{$\begin{array}{l}\text { Control group } \\
\qquad \times n=20^{66}\end{array}$} & \multicolumn{2}{|c|}{$\begin{array}{l}\text { Study group } \\
{ }^{66} \mathrm{n}=20^{66}\end{array}$} & \multirow[t]{2}{*}{$\mathbf{P}$} \\
\hline & No. & $\%$ & No. & $\%$ & \\
\hline Spontaneous ovulation & 2 & 10.0 & 1 & 5.0 & 0.12 \\
\hline Immature oocytes & 6 & 30.0 & 3 & 15.0 & $0.032^{*}$ \\
\hline Failed fertilization & 0 & 0.0 & 1 & 5.0 & \\
\hline Failed cleavage & 0 & 0.0 & 1 & 5.0 & \\
\hline Poor responders & 4 & 20.0 & 0 & 0.0 & \\
\hline
\end{tabular}

* Statistically significant

Table VII : Statistically significant effects of $\mathrm{N}$-acetyl cysteine on different parameters measured in both groups.

\begin{tabular}{|c|c|c|c|}
\hline Parameter & Control group & Study group & $P$ \\
\hline Number of ampoules used & $20.0 \pm 3.43$ & $18.3 \pm 2.08$ & $0.03 *$ \\
\hline Oestrogen " $\mathrm{pg} / \mathrm{m}$ l" on the daty of $\mathrm{HCG}$ & $793.92 \pm 783.01$ & $1375.35 \pm 1206.04$ & $0.042 \%$ \\
\hline Mattre oocytes M2 & 35 & 75 & $0.001 \%$ \\
\hline $\begin{array}{l}\text { Mean number of fertilized oocytes per } \\
\text { case }\end{array}$ & $3.0 \pm 1.41^{\circ}$ & $4.0 \pm 4.81$ & $0.01^{*}$ \\
\hline $\begin{array}{l}\text { Mein number of embryos transferted } \\
\text { per case }\end{array}$ & $2.88 \pm 1.25$ & $3.21 \pm 2.58$ & $0.001 *$ \\
\hline Cancellation rate & 60.0 & 30.0 & $0.021:$ \\
\hline
\end{tabular}

* Statistically significant 
Table VIII : Comparison between pregnant and non-pregnant fermales in both groups regarding follicular fluid testosterone.

\begin{tabular}{|c|c|c|c|c|}
\hline \multirow[t]{2}{*}{.} & \multicolumn{2}{|c|}{$\begin{array}{c}\text { Control group } \\
\qquad n=20 " 6\end{array}$} & \multicolumn{2}{|c|}{$\begin{array}{l}\text { Study group } \\
\text { "n=20" }\end{array}$} \\
\hline & $\begin{array}{l}\text { Pregnant } \\
" n=5 \text { " }\end{array}$ & $\begin{array}{c}\text { Non-Pregnant } \\
\qquad n=15 \text { " }\end{array}$ & $\begin{array}{l}\text { Pregnant } \\
" n=4 "\end{array}$ & $\begin{array}{l}\text { Non-Pregnant } \\
\qquad " \mathrm{n}=16^{\circ}\end{array}$ \\
\hline $\begin{array}{l}\text { Follicular } \\
\text { testosterone } \\
\text { "ng/ml" }\end{array}$ & $17.03 \pm 8.2$ & $17.82 \pm 3.69$ & $14.1 \pm 8.25$ & $14.8 \pm 9.6$ \\
\hline $\mathrm{t} \cdot \mathrm{p}$ & \multicolumn{2}{|c|}{$0.36,0.41$} & \multicolumn{2}{|c|}{$0.51,0.36$} \\
\hline
\end{tabular}

\section{DISCUSSION}

In the last few decades there has been extensive research aiming at improving the results of controlled ovarian hyperstimulation $(\mathrm{COH})$ protocols. This led to the introduction of various drugs both hormonl and nonhormonal starting from clomiphene citrate and human menopausal gonadotropins (hMG) till the introduction of gonadotropin releasing hormone agonists and antagonists. Pharmaceutical agents also included the so named "adjuvants to ovarian stimulants" aiming at improving patients response to $\mathrm{COH}$.

In addition, various induction protocols were used aiming at improving patients response and minimizing the side effects of $\mathrm{COH}$. After the introduction of the concept of "friendly IVF" there have been various trials to maximize the results of IVF programs with minimization of the costs and side effects (1)

To the best of our knowledge, this is the first trial in which $\mathrm{N}$-acetyl cysteine is used as an adjuvant therapy to hMG induction protocol in cases prepared for ICSI and assessing its effect on various parameters including follicular fluid testosterone level.
During a total of 40 cycles we were able 10 retrieve 110 mature oocytes ( 2.75 per cycle) and the total number of cmbryos transferred was 68 embryos in 22 patients. This resulted in a pregnancy rate of $22.5 \%$ per cycle. However, in a systematic review of 1800 cycles of natural cycle IVF done by Pelinck el al in 2002 , the average pregnancy rate was $7.2 \%$ per started cycle. In our study, we were able to do embryo transfer in $55 \%$ of the cases while in the Pelinck et al. embryo transfer was done in only $45.5 \%$ (2).

Our results were comparable to those of a randomized study using clomiphene citrate in cases prepared for IVF, in which embryos were translerred in $53 \%$ but the pregnancy rate was only $18 \%$ (3).

The present study has demonstrated that administration of NAC as an adjuvant therapy to the hMG controlled ovarian hyperstimulation was associated with: larger number of mature oocyles, higher number of fertilizaed oocytes and lower cancellation rates.

However, all these improvements in cycle parameters did not lead to a significant increase in the pregnancy rates, which may be explained by the small sample size and the diversity of factors that affect the occurrence of pregnancy.

The antioxidant effects of NAC may explain the 
above mentioned beneficial effects. Previous literature has demonstrated these actions in-vitro in tissue cultures of procine and human ovarian tissues. NAC has been used to suppress cell death in human ovarian tissue cultures and as well in inhibiting apoptosis in human male germ cells in vitro (13). In a study conducted by Otala et al (2002), NAC was found to inhibit apoptosis in human ovarian cell culture (15). In another study conducted by Erkkilä et al (1998) NAC was found to suppress programmed cell death in human testicular germ cells in vitro (16).

To our knowledge, the first published paper on the use of NAC in PCOS patients was by Fulghesu et al in 2002. In this preliminary study, NAC was given at a dose of 1.8 grams per day aiming at improving insulin sensitivity in 31 PCOS patients. They demonstrated a significant improvement in insulin sensitivity and a significant fall in plasma testosterone level in these patients. However, ovulation and follicular fluid testosterone were not monitored in this study (14)

The first study that utilized NAC as an adjuvant in cases prepared for ICSI was done in El-Shatby university maternity hospital in 2004. The research was aiming at studying the effect of NAC on oocyte maturity, granulosa cells mitotic figures, fertilization and pregnancy rates. It was a randomized cristrolled study done on 40 non-PCO patients who were equally divided into two groups. NAC was given at a dose of $1.2 \mathrm{gm} /$ day in addition to $100 \mathrm{mg}$ of clomiphene citrate to patients in the study group while the control group used clomiphene citrate only. The researchers demonstrated a higher pregnancy rate $(25 \%)$ in the study group compared to the control group $(15 \%)$ but this difference was not statistically significant. The mean number of mature oocytes was insignificantly higher in the control group (1.25) than the study group (0.85). Cancellation rates were equal in both groups $(50 \%)$. The effect on the granulosa cells and fertuization rates were almost similar in both groups ${ }^{(17)}$.
There was another study that was conducted by Rizk et al in 2004 on the use of NAC in PCOS patients. The objective of this study was to evaluate the effect of NAC as an adjuvant therapy in subjects with PCOS resistant to clomiphene citrate. It was a placebo controlled double blind randomized trial, conducted upon 150 PCOS patients diagnoed as clomiphene citrate resistant, aged 18-39 years undergoing ovulation induction and natural intercourse. Patients were assigned randomly to receive NAC $1.2 \mathrm{gm} /$ day (group I) or placebo (group II) with clomiphene citrate $100 \mathrm{mg} /$ day for 5 days starting at day 3 of the cycle. Primary outcome measure was the number of follicles and pregnancy rates. The results of the study showed that the combination of clomiphene citrate and NAC significantly increased both ovulation rate and pregnancy rate in women with clomiphene citratc resistant $\mathrm{PCOS}(49.3 \%$ vs. $1.3 \%$ and $21.3 \%$ vs. $0 \%$ respectively). No cases of ovarian hyperstimulation syndrome were reported in the NAC group. It was concluded from this study that NAC as an adjuvant to clomiphene citrate was more effective than placebo for clomiphene citrate resistant patients with PCOS and that it is a safe and well tolerated drug (18).

With the introduction of IVF, a number of studics have focussed on analyzing follicular fluid from women receiving ovarian hyperstimulation, aiming at obtaining prognostic parameters for selecting the hest oocytes with the greatest likelihood of resulting in successful implantation. However the results of a large number of studies are conflicting.

To demonstrate the importance of measuring follicular fluid steroids Haning et al in 1993. measured hormonal levels in systemic arteries. ovarian veins, peripheral veins and follicular fluid. According to their conclusion, they found overwhelming evidence that the ovarian follicles are compartments that are not in equilibrium with arterial or venous blood. The metabolism of steroids coecurs at high concentmations without the intermediates 
reaching equilibrium with peripheral bllod steroids. Thus, measurements of follicular fluid steroid concentrations are crucial for understanding the follicular metabolism ${ }^{(9)}$.

The present work showed a lower follicular fluid testosterone level in the NAC group (mean 14.8 $\mathrm{ng} / \mathrm{ml}$ ) than the control group (mean $17.43 \mathrm{ng} / \mathrm{ml}$ ). This difference was statistically insignificant which may be attributed to the small sample size. Moreover, pregnant females had a slightly lower level of follicular fluid testosterone $(15.72 \mathrm{ng} / \mathrm{ml})$ than non-pregnant females $(15.93 \mathrm{ng} / \mathrm{ml}$ ), but still the difference was statistically insignificant. Andersen also found this non-significant decrease in the follicular fluid testosterone between pregnant and non-pregnant females (19).

On the other hand, Tarlatzis et al in 1993 conducted a study on women using fixed dose hMG induction protocol (24 cycles). The researchers demonstrated a significantly lower follicular fluid testosterone level in follicles with mature oocytes $(13.13 \mathrm{ng} / \mathrm{ml})$ in comparison to follicles of oocyters with intermediate maturity $(17.05 \mathrm{ng} / \mathrm{ml})$. They also showed a significantly lower follicular fluid testosterone levels in follicles with better quality oocytes and in those with higher frtilization rates (20).

On the other hand, other researchers reported no correlation at all between follicular fluid testosterone levels and oocyte maturity or fertilization rates $(21,22)$. Botero-Ruiz et al correlated the successful out come of IVF cycles to significantly higher follicular fluid oestradiol (E2) levels (23).

In the present study as well as most of the above mentioned studies, no procedure was taken to identify the exact follicle that resulted in pregnancy. After embryo transfer of more than one embryo technically it is impossible to pin point the embryos that resulted in pregnancy. So actually we are measuring the hormonal profile of a heterogenous group of follicles each of them has different hormonal concentrations. Some of these follicles contain mature oocytes and others are containing immature oocytes. Also some of them contain oocytes that resulted in pregnancy and others contain oocytes that lailed to result in pregnancy. This can affect the significance of the measured hormones as an indicator of the maturity of the oocytes.

Andersen inhis study aimed at identifying the exact follicle that resulted in pregnancy and studying its hormonal profile. So he used only follicular lluid from those patients in which the number of embryos transferred equals the number of implantations. $\mathrm{Hc}$ demonstrated that the ratio of (E2) to testosterone is significantly higher in those follicles resulting in pregnancies. So he concluded that this ratio and not the absolute levels of these hormones that can bo utilized as markers of the best oocytes (19).

The ratio of E2/testosterone in the follicular fluid may reflect the effectiveness of the granulosa cells to convert androgens to E2. MeNatty et at in 1979 showed that the number of granulosa eells within the follicle is correlated to the E2 / androgen ratio and this is also correlated to the stage of oocyte maturity. Atresia may result if the follicle contains less than the optimal amount of granulosa cells.

According to McNatty's results, and the effect of NAC on inhibiting apoptosis in granulosa cells which have been demonstrated in vitro in tissue cultures. this may be the mechanism by which NAC decreases follicular fluid testosterone levels $(9)$.

Finally, in the present study, NAC was a well tolerated drug by all patients with no manifest side effects reported from any case in the study group.

\section{CONCLUSION}

The use of NAC as an adjuvant to the low fixed dose gonadotropin protocol in cases prepared for ICSI improved cycle parameters but it did not result in a significant effect on follicular fluid testosterone concentrations or the pregnancy rates. 


\section{REFERENCES}

1. Olivennes F, Frydman R. Friendly IVF: the way of the future? 1998; 13(55): 1121-1124.

2. Pelinck M., Hoek A., Simons A., et al. Efficacy of natural cycle IVF: a review of the literature. Hum. Reprod. Update. 2002; 3(2): 129-139.

3. Ingerslev H., Hojgaard A., Hindkjaer J., et al. A randomized study comparing IVF in the unstimulated cycle with IVF following clomiphene citrate. Hum. Reprod. 2001; 16(4): 696-702.

4. Erickson G., Magoffin D., Dyer C., et al. The ovarian androgen producing cells: a review of structure/ function relatinship. Endocr. Rev. 1985; 6: 371.

5. Greisen S., Lebet T., Ovesen P. Effects of androstenedione, insulin and luteinizing hormone on steroidogenesis in human granulosa luteal cells. Hum. Reprod. 2001; 16: 2061.

6. McNatty K., Smith D., Makris A., et al. The microenvironment in human antral follicle: interrelationships among the steroid in antral fluid, the population of granulosa cells and the status of oocytes in vivo and in vitro. J. Clin. Endocrinol. Metab. 1979; 49: 851-60.

7. Van Dessel T., Schipper I., Pache D., et al. Normal human follicle development: an evaluation of correlations with oestradiol, androstenedione and progesterone concentrations in individual follicles. Clin. Endocrinol. 1996; 44: 191-198.

8. Nendoza C., Cremades N., Ruiz-Requena E., et al. Relationship between fertilization results after ICSI and intrafollicular steroids, pituitary hormones and cytokine concentrations. Hum. Reprod. 1999; 14(3): 628-635.

9. Haning R., Richard J., Hacketl J, et al. Testosterone, a follicular regulator: key to anovulation. J. Clin. Endocrinol. Metab. 1993; 77: 710-715.

10. Teissier M., Chable H., Paulhac S., et al. Recombinant human follicle stimulationg hormone versus human menopausal gonadotrophin induction: effects in mature follicle endocrinology. Hum. Reprod. 1999; 14(9): 2236-2241.

11. Chandra J, Samali A, Orrenius S, Triggering and modulation of apoptosis by oxidative stress. Free Radic Biol Med. 2000; 29(3-4): 323-333.

12. Hovatta O., Silye R., Abir R., et al. Extracellular matrix improves survival of both stored and fresh human primordial and primary ovarian follicles in long-term culture. Hum. Reprod., 1997; 12: 1032-1036.

13. Lee C.K., Weaks R.L., Johnson G.A., et al. Effects of protease inhibitors and antioxidants on in viro survival of porcine primordial germ cells. Biol. Reprod. 2000; 63: 887-897.

14. Fulghesu A. M., Ciampelli M., Muzj G.. et al. $\mathrm{N}$-acetyl-cycteine treament improves insulin sensitivity in women with polycystic ovary syndrome. Fertil Steril. 2002; 77(6): 1128-1135.

15. Otala M., Erkkilä K., Tuuri T., et al. Cell death and its suppression in human ovarian tissue culture. Mol. Hum. Rep. 2002; 8: 228-236.

16. Erkkilä K., Hirvonen V., Wuokko E., et al. L. $\mathrm{N}$-Acetyl-L-cysteine inhibits apoptosis in human male germ cells in vitro. J. Clin. Endocrinol. Metab. 1998; 83: 2523-2531.

17. Tappozada $T$. The effect of acetyl cysleine administration in ovulation induction and assisted reproduction in clomiphene citrate stimulated patients. Msc thesis, Alexandria universtiy. 2004.

18. Rizk A. Y., Bedaiwy M. A., Al-Inany H. G. $\mathrm{N}$-Acetyl cysteine is a novel adjuvant to clomiphene citrate in resistant polycystic ovary syndrome patients. $19^{\text {th }}$ annual meeting of the Eurpean society of Human Reproduction and Embryology 2004.

19. Andersen C. Characteristics of human follicular fluid associated with successful conception after in vitro fertilization. J. Clin. Endocrinol. Metab. 1993; 77: $1227-1234$.

20. Tarlatizis B.C., Pazaitou K., Bili H., et al. Growih hormone, oestradiol, progesterone and testosterone in follicular fluid after ovarian stimulation with various regimes for assisted reproduction. Hum. Reprod. 1993; 8: 1612-1616.

21. Enien W., Chantler E., Seif M., et al. Human ovarian granulosa cells and follicular fluid indices: the relationship to oocyte maturity and fertilization in vito. Hum. Reprod. 1998; 13: 1303-1306.

22. Guerrero E., Sheim P., Asid R., et al. effect of gonadotrophin-releasing hormone agonist on luteinizing hormone receptors and steroidogenesis in ovarian cells. Fertil. Steril. 1993; 50: 803-809.

23. Botero-Ruiz W., Laufer N., DeCherney A. H., el al. The relationship between follicular fluid steroids concentration and successful fertilization of human oocytes in viro. Fertil. Steril. 1984; 41: 820-806. 